\title{
Novel Influenza HINI in Pregnancy: Report of a Diagnosed Case in Bangladesh
}

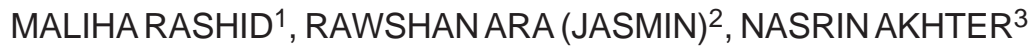

\begin{abstract}
Category C pandemic flu 2009 \{H1N1 influenza), the disease that has reached pandemic proportions, holds everyone at risk today H1N1 influenza and pregnancy together, poses a greater risk for pregnant women and this deserves special attention. A swine flu pregnancy can be life threatening for both the mother and the baby. During the current pandemic of H1N1 influenza, few cases of H1N1 have been reported in pregnancy cases. We report one interesting case of H1N1 influenza, which was the only confirmed case of H1N1 Flu who survived with pregnancy in Bangladesh. Widespread vaccination, when available, prompt diagnosis, and adequate treatment with antiviral medications when infection occurs can save the life of the mother and the baby.
\end{abstract}

Keywords: Novel influenza H1N1, pregnancy

\section{Introduction}

Although the name 'swine flu ${ }^{1}$ brings up a lot of extra fear and worry, it is influenza A H1N1 virus, which causes typical seasonal flu symptoms ${ }^{1}$. But current swine influenza $A(H 1 N 1)$ virus is new and most of us don't have any immunity to it. That is why it so easily became a pandemic virus with the ability to cause a global outbreak. Pregnant women are considerably more likely to develop serious complications from H1N1 flu. The World Health Organization states that up to $10 \%$ of all hospitalized patients with H1N1 flu are women who are more than three months pregnant. In pregnancy, the immune system is naturally suppressed ${ }^{2}$. This means that pregnant women are more likely to catch $\mathrm{H} 1 \mathrm{~N} 1 \mathrm{flu}$, and if they do catch it, they are more likely to develop complications. The pregnant woman experiences innumerable changes in her lung functioning, in the second and third trimesters of her pregnancy period. An enlarged womb leaves little room for the expansion of the lungs and restricts coughing capacity. The lungs feel constricted and its slacked functioning impairs its natural ability to deal with airborne flu viruses. Most pregnant women experience breathing difficulties during pregnancy, but a swine flu pregnancy just makes it critically worse $^{3}$. The swine flu pregnancy risks include the risk of pneumonitis. Swine flu in pregnancy also increases the risks of dehydration, due to diarrhea and vomiting, in the mother.

In pregnant women, these are more likely to happen in the second and third trimester. If a pregnant woman develops a complication of H1N1 flu, such as pneumonitis, this will lead to premature labour or miscarriage. There is not yet enough information to know precisely how likely these birth risks are.

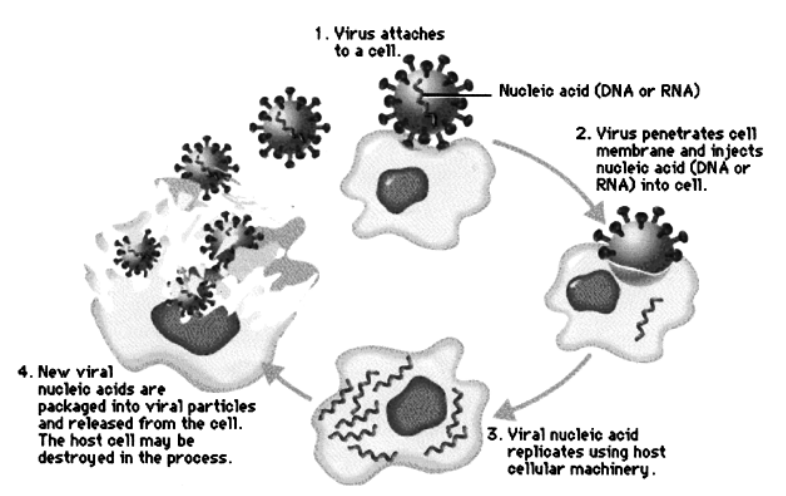

Fig - 1: H1N1 virus replication

\section{Case}

Mrs. Sazeda Rahman 32 years old, Para 1(LS.C.S) +1 (sp. Abortion), 3rd gravida admitted on $23^{\text {rd }}$ September '09 was presented with pregnancy for 36

1. Ex. Professor \& Head of the dept. Obstetrics \& Gynaecology. DMCH

2. In Door Medical Officer, Dhaka Medical College Hospital, Dhaka.

3. Assistant Prof. Gynae \& Obs., Sir Salimullah Medical College, Dhaka. 
weeks, fever, running nose and cough for three days and respiratory distress for one day. Her L.M.P was on 11-01-09 and accordingly her E.D.D was 18-1009. She was in regular antenatal checkup and is a member of a high socio economic family. Her pregnancy was uneventful. But for last three days she had developed low grade continued fever. Her fever was associated with generalized body ache and was not associated with chills \& rigor or joint pain \& she had no rash. Fever was relieved after taking paracetamol Patient also suffered from running nose and cough. Cough was initially dry but later on it became productive with yellowish colored sputum. She had mild respiratory distress for last one day which aggravated on lying \& reduced on sitting position. She had no diarrhea or vomiting or no H/O burning sensation during micturition. She was a known case of B- thalassaemia minor \& has undergone total thyroidectomy due to multinodular goiter and is on tab thyroxin [100 microgram daily]. On Examination, the patient was anxious and ill looking \& flushed. Her built was average, she was cooperative and felt comfort on sitting position. She was mildly anemic, her pulse rate was 96 beats $/ \mathrm{min}$, BP $130 / 80 \mathrm{~mm}$ of $\mathrm{Hg}$ and temp was $102^{\circ} \mathrm{F}$. Examination of respiratory system revealed Respiratory rate was 22 breaths /min with mild dyspnoea. Coarse creps was present in both lungs in mid \& lower zones.

On per abdominal examination symphysiofundal height was $36 \mathrm{~cm}$ and presentation was Cephalic \& head was not engaged. Her FHR was regular, 136 beats/min. Other systemic examination revealed normal findings.

Her inv finding was; Total count of WBC on24/09/09: 7600/Cu, Mm; Polymorph: 65\%; lymphocytes: 31\%; $\mathrm{Hb}: 10.3 \mathrm{gm} / \mathrm{dl}$; S. free T4 level on 10-09-09: 0.9 nano gram /dl; S. TSH level on 10-09-0: 5.6 micro IU/ml; Chest X-ray PA view (with shield) revealed cloudy opacity is in all zones of both lung fields suggestive of bilateral pneumonitis. Her Nasal swab was collected \& sent for PCR for H1N1 Virus on 26-09-09 \& finding was Positive. So, she was a diagnosed case of Pandemic Flu 2009 Category C.

An emergency board was arranged immediately. The members of the board were a pulmonologist, a member from the national core committee for swine flu, an $1 \mathrm{CU}$ specialist \& a gynecologist. They advised as follows:
Strict isolation in cabin; Minimum number of care provider (preferable single) with maximum service; N95 mask for patient, her attendants \& health providers; SPO2 monitoring; Regular monitor of vital signs; Inj Meropenum 1 gm 1 amp IV 12 hrly; Inj Amikacin 500 mg 1 amp IV 12 hourly; Double dose of Tami flu 75mg 2 cap 12 hourly for 5 days; Immediate caesarian section; Arrangement for ICU care for mother if required.

Emergency LSCS was done on 26-09-09 at 8:55 pm under spinal anesthesia. All the members of the operation team used N95mask. A female baby of $2{ }_{r} 1$ $\mathrm{kg}$, with good APGAR score was delivered. Baby was treated with Osaltamivir ( $2 \mathrm{mg} / \mathrm{kg}$ body wt) prophylactically. Her post operative period was uneventful. Her cough subsided during 7th POD. She was discharged from hospital on 9th POD with healthy baby \& with advice to come for postnatal follow up.

\section{Discussion}

The discussion about the case, suggest that, as with seasonal influenza, pregnant women constitute a population at risk for morbidity and mortality. Patients with $\mathrm{H} 1 \mathrm{~N} 1$ viral infection present with acute respiratory symptoms - dry cough sore throat, nasal congestion, and fever. Almost one third of them report contact with an ill individual on admission ${ }^{4}$. The symptoms are nonspecific such that it is not surprising that many patients later confirmed to have swine flu (including those in our report), had their symptoms attributed to the common cold when they had been seen earlier ${ }^{516}$. The Centre for Disease Control [CDC] recommends that clinicians should use nasopharyngeal swabs for rapid detection of antigens for influenzas $A$ and $B$ in patients with fever and respiratory symptoms. If influenza A virus infection is found, the specimen should be sent to a state public health laboratory for additional testing to identify $\mathrm{H} 1 \mathrm{~N} 1$ virus using the realtime PCR technique which is currently recommended for laboratory confirmation of $\mathrm{H} 1 \mathrm{~N} 1$ viral infection [8]. Antiviral therapy is often delayed for pregnant patients ${ }^{78}$ and it should be reinforced that antiviral therapy should be started as soon as possible based only on clinical presentation of fever and sore throat or cough without waiting to obtain results of laboratory testing, unless another cause of symptoms is reasonably suspected ${ }^{9}$. It is preferable to start antiviral therapy within 48 hours of the first influenza-related symptoms and continue for 5 days. 
H1N1 virus is sensitive to both oseltamivir (75 mg twice a day) and zanamivir (two $5 \mathrm{mg}$ inhalations twice a day ${ }^{10}$. Due to systemic absorption arid more experience with oseltamivir, it is the preferred medication. The benefit of treating the influenza outweighs any the theoretical risk for the fetus. In addition to an antiviral preparation, acetaminophen should also be started because fever may be associated with neural tube defect, neonatal seizures, encephalopathy, cerebral palsy, and neonatal death $^{11,12}$. It is recommended to treat severe cases of H1N1 infection in a hospital, using respiratory support with supplemental oxygen and mechanical ventilation as required. Antibiotic supplementation should be guided by the presence of pneumonia depending on the patterns of resistance in the region ${ }^{13}$. Since pneumococcal pneumonia is frequently a secondary invader, pregnant women who are in risk groups should also be vaccinated against that organism. Current CDC recommendation suggests that pregnant women who had contact with someone suspected of infection with novel H1N1 influenza virus should receive prophylactic treatment with either oseltamivir (75 mg daily) or zanamivir (two $5 \mathrm{mg}$ inhalations daily) for 10 days. The CDC states that zanamivir is preferable due to its low systemic absorption, but because of its inhaled route of administration, respiratory complications must be considered $^{14}$. The advisory committee on immunization safety recommends that pregnant women be included in primary targeted groups for vaccination $^{12}$.

Vaccination is also recommended for household contacts of pregnant women; however, chemoprophylaxis is not indicated for otherwise healthy people exposed to influenza. Early empiric treatment should be started if symptoms arise ${ }^{13}$ currently all subtyped influenza A viruses reported to CDC (99\% of all specimens sent to CDC) are $\mathrm{H}_{1 \mathrm{~N}}{ }^{14}$, Obstetricians should be prepared to diagnose and rapidly treat $\mathrm{H} 1 \mathrm{~N} 1$ and, now with the availability of H1N1 vaccine, to be proactive with vaccination programs to stop the spread of the infection.

\section{Conclusion}

The combination of HINI influenza (swine flu) and pregnancy is potentially risky. If someone are pregnant and think she may have H1N1 flu or had close contact with someone who has known or suspected H1N1 flu, recommend treatment with an antiviral medication known to be effective against the virus- oseltamivir (Tamiflu), zanamivir (Relenza), as inhaler. Ideally, the medication should be started within 48 hours of development of symptoms.

\section{References}

1. L. Dodds, McNeil S. A., Fell D. B., et al., "Impact of influenza exposure on rates of hospital admissions and physician visits because of respiratory illness among pregnant women," Canadian Medical Association Journal, vol. 176, no. 4, pp. 463-468,2007.

2. Vaillant L., La Ruche G., Tarantola A., Barboza P., "Epidemiology of fatal cases associated with pandemic H1N1 influenza 2009," Euro Surveillance, vol. 14, no. 33, Article ID 19309, 2009

3. Rasmussen S. A,. Jamieson D. J, MacFarlane K., Cragan J. Williams D., J, , and Henderson Z, "Pandemic influenza and pregnant women: summary of a meeting of experts," American Journal of Public Health, vol. 99, supplement 2, pp. S248-S254,2009,

4. Centers for Disease Control and Prevention ICDC), "Hospitalized patients with novel influenza A(H1N1) virus infection-California, April-May, 2009," Morbidity and Mortality Weekly Report, vol. 59, pp. 536-541, 2009.

5. Centers for Disease Control and Prevention (CDC), "Novel influenza A(H1N1) virus infection in three pregnant women-United States, AprilMay 2009," Morbidity and Mortality Weekly Report, vol. 58, pp. 497-500, 2009.

6. Centers for Disease Control and Prevention (CDC), "Erratum: novel influenza A(H1N1) virus infection in three pregnant women-United States. April-May 2009," Morbidity and Mortality Weekly Report, vol. 58, p. 541, 2009.

7. Jamieson, D, J. M. A. Honein, S. $A_{h}$ Rasmussen, et al., "H1N1 2009 influenza virus infection during pregnancy in the USA. The Lancet, vol. 374, no, 9688, pp. 451-453, 2009.

8. Centers for Disease Control and Prevention (CDC), "Interim guidance on specimen collection, processing, and testing for patients with suspected novel influenza (H1N1) virus infection," December 2009, http://www.cdc.gov/h1n1flu/ specimencollection. htm. 
9. Centers for Disease Control and Prevention (CDC), "Pregnant women and novel influenza $A$ (H1N1) virus: considerations for clinicians," December 2009 http//www.cdc.gov/h1n1flu/ clinician pregnant.htm.

10. Matheson, N. J. A. R, Harnden, R, Perera, A. Sheikh, and M. Symmonds- Abrahams "Neuraminidase inhibitors for preventing and treating influenza in children," Cochran Database of Systematic Reviews, no. 1, Article ID CD001265, 2007.

11. World Health Organization (WHO), "Clinical management of human infection with new influenza (H1N1) virus: initial guidance" May 2009.
12. Centers for Disease Control and Prevention (CDC), "Update: Influenza Activity_ United Slates, April-August, 2009" Morbidity and Mortality Weekly Report, vol. 58, pp. 1009-1012, 2009.

13. Infectious Diseases Society of America (IDSA), "Influenza H1N1: frontline questions \& expert opinion answers,"December2009,http://www. idsociety.org/Content.aspxi= 15743

14. Centers for Disease Control and Prevention (CDC), "2008- 2009 influenza season week 50 ending December 19, 2009,"December 2009, http://www.cdc.gov/flu/weekiy 